\title{
A CEPHALOMETRIC STUDY IN SOUTHERN PUNJAB
}

1. Department of Human Anatomy, Faculty of Medicine, Umm al Qura University, Makkah, Saudi Arabia

2. Department of Pathology,

Multan Medical and Dental College, Multan, Pakistan

3. Department of Human Anatomy, Faculty of Medicine, Umm al Qura University, Makkah, Saudi Arabia

Correspondence Address: Dr. Mohammad Afzal Khan

Department of Human Anatomy, Faculty of Medicine, Umm al Qura University,

P.O.Box: 7607. Makkah, Saudi Arabia dr.khan1948@gmail.com

Article received on: 28/01/2015

Accepted for publication: 06/07/2015

Received after proof reading: 09/09/2015

\section{Dr. Mohammad Afzal Khan', Dr. Muhammad Naeem Chaudhry², Dr. Faris Mohammed Nour Altaf ${ }^{3}$}

ABSTRACT... Background: Morphological characteristics of various races and population groups usually appear in geographical knots and clusters. Standardized cephalometricrecords are immensely valuable for clinical and forensic purposes. In spite of its clinical significance no data is available about the cephalic indices and prevalence of cephalic phenotypes in Southern Punjab. Objectives: This study was undertaken to record baseline cephalometric data, cephalic indices and craniotypes. Study design: A cross-sectional population study. Place and duration of study: The study was carried out at the Multan Medical and Dental College, Multan and took about fourteen months to complete. Material and methods: The study was conducted on 672 adult individuals ( 430 males and 242 females) from in and around the city of Multan in Southern Punjab. Linear measurements of the head including maximum cranial length (glabella-inion length), maximum cranial breadth (maximum bi-parietal diameter) and maximum auricular head height were recorded using a digital spreading caliper. Results of measurements were expressed as mean \pm SD. Comparison of the mean values and various proportions between sexes was performed. The horizontal, vertical and transverse cranial indices were calculated using these measurements. Craniotyping was based on the ranges in various cephalic indices. Results: Differences regarding the mean of cranial length, cranial breadth and height were significantly larger in males as compared to females $(P<0.001)$. The mean vertical, horizontal and transverse cephalic indices in the males and females were $79.13 \pm 5.56,78.31 \pm 5.19$, $103 \pm 7.78$ and $78.32 \pm 6.40,78.32 \pm 4.67,100 \pm 8.67$ respectively.Most of the samples depicted craniotypes as mesocephalic and dolichocephalic both in the males and the females. Conclusion: The study provides baseline cephalometric data from a population of Southern Punjab that may have its potential in clinical application and future research.

Key words: Cephalometry, cephalic index, craniotypes, cranial measurements.

Article Citation: Khan MA, Chaudhry MN, AltafFMN. A cephalometric study in southern Punjab. Professional Med J 2015;22(9):1203-1207. DOI: 10.17957/TPMJ/15.2792

\section{INTRODUCTION}

Morphological features of different races and ethnic groups are not randomly distributed but appear in geographic clusters. ${ }^{1}$ Methods currently availed for metric evaluation of the craniofacial form includes anthropometry, cephalometry, ultrasound, computed tomographic, scanning magnetic imaging and optical surface scanning. Arguably, cephalometry remains the most useful technique in the investigation of the craniofacial morphology because of its validity and practicality. ${ }^{2} \mathrm{On}$ the basis of cephalic index $(\mathrm{Cl})$ head shapes can be grouped into four categories: dolichocephalic, brachycephalic, mesocephalic and hyperbrachycephalic. , $^{3,4}$

Standardized cephalometric records are helpful in making a comparison between patients and the normal population ${ }^{5}$ and are useful in pediatrics, forensic medicine and plastic and orodental surgery. ${ }^{6}$ Since geographic, racial and dietary differences exist amongst different population groups information about morphometric characteristics becomes important for purposes of comparison. Such knowledge is also very useful in studies pertaining to primate phylogeny. Age and population specific data on cranial morphometry are not only useful in clinical practice as indicators of growth and development but also in determining changes in size and shape or abnormalities of the crania. ${ }^{7}$

Notwithstanding the forensic importance and clinical significance of morphometric data and 
whereas several studies are available from different countries the cephalic indices and prevalence of cephalic phenotypes in Southern Punjab has not been studied. This study was therefore undertaken to record baseline cephalometric data, cephalic indices and craniotypes for clinical use and future reference.

\section{MATERIAL AND METHODS}

It was a cross-sectional study conducted on 672 adult individuals ( 430 males and 242 females) that volunteered from in and around the city of Multan in Southern Punjab. Consent of the participants and approval from the ethical committee were obtained. Healthy subjects who had no apparent craniofacial deformity and belonging to different socio-economic strata were selected. The age of the subjects ranged between 20 and 56 years. Following linear measurements were recorded:

1: Maximum Cranial Length $(M C R)$ : It is the straight distance between the glabella (a prominent point at the root of the nose and the inion (a prominent point on the occipital bone), both in the median sagittal plane. One tip of the calipers was placed at the glabella and then the other tip of the calipers was allowed to slip posteriorly onto the occipital bone in the median sagittal plane to reach the maximum posteriorexpanse of the skull.

2: Maximum Cranial Breadth (MCB): It is the maximum biparietal distance. The calipers tips were slid downwards along the lateral sides of the parietal bones to achieve the maximum width.

These measurements were taken using a digital calipers (Mitutoyo, Japan) to the nearest $0.01 \mathrm{~mm}$.

3: Maximum Auricular head Height (MAH): It is the distance between bregma (the highest point of the vortex) and the external acoustic meatus. Todd's head spanner was used to record measurements on both sides.

Measurements were taken three times and their mean was recorded as the final observation. The Statistical Package for Social Sciences (SPSS), 15 th version was used to analyze the data and the results were expressed as mean \pm SD. The mean values were compared for males and females for different measurements using the ' $\mathrm{t}$ ' test and the ' $z$ ' test. $P$ value $<0.05$ was considered statistically significant.

The following cranial indices were calculated using the above measurements:

A: Horizontal cephalic index $(\mathrm{HCl})=$ Maximum cranial breadth/ Maximum cranial length $x$ $100 \%$.

B: Vertical cephalic index $(\mathrm{VCl})=$ Maximum auricular head height/ Maximum cranial length $x 100 \%$.

C: Transverse cephalic index $(T C l)=$ Maximum auricular head height/ Maximum cranial breadth $\times 100 \%$.

Craniotyping was based on the ranges in horizontal,vertical and transverse cephalic indices as follows: $: 8$

- According to the horizontal cephalic index $(\mathrm{HCl})$ headshapes were classified as

- Dolichocephalic $(71.0<\mathrm{HCl}>75.9)$,

- Mesocephalic $(76.0<\mathrm{HCl}>80.9)$,

- Brachycephalic $(81.0<\mathrm{HCl}>85.90)$ and

- Hyperbrachycephalic $(86.0<\mathrm{HCl})$;

- According to the vertical cephalic index (VCl) head shapes were classified as

- Chamaecephalic $(57.9>\mathrm{VCl})$,

- Orthocephalic $(58.0<\mathrm{VCl}>62.9)$ and

- Hypsicephalic $(63<\mathrm{VCl})$;

- According to the transverse cephalic index (TCI) head shapeswere classified as

- Tapeiocephalic $(78.9>\mathrm{TCl})$,

- Metriocephalic79.0 < TCl > 84.9) and

- Acrocephalic $(85.0<\mathrm{TCl})$.

\section{RESULTS}

The mean ages of the subjects (male: $42 \pm 12.31$; female $37 \pm 14.43$ ) were not significantly different between the two sexes. However,the differences among the male and female group of subjects regarding the mean maximum cranial length (MCL), maximum cranial breadth (MCB) and maximum auricular head height $(\mathrm{MHH})$ were found to be significantly more in the males as compared to the females. 


\begin{tabular}{|c|c|c|c|}
\hline Parameter & $\begin{array}{c}\text { Male } \\
\text { Mean } \pm \text { SD }(n=430)\end{array}$ & $\begin{array}{c}\text { Female } \\
\text { Mean } \pm \text { SD }(n=242)\end{array}$ & $\begin{array}{c}\text { Combined } \\
\text { Mean } \pm \text { SD }(n=672)\end{array}$ \\
\hline Cranial length & $188.03 \pm 9.71^{*}$ & $173 \pm 7.87$ & $180.30 \pm 8.84$ \\
\hline Cranial breadth & $151.72 \pm 6.33^{*}$ & $144.14 \pm 5.42$ & $148 \pm 5.76$ \\
\hline Auricular head height & $144 \pm 9.87^{*}$ & $139 \pm 7.98$ & $141 \pm 8.43$ \\
\hline Horizontal cephalic index $(\mathrm{HCl})$ & $79.13 \pm 5.56^{\star}$ & $78.32 \pm 6.40$ & $78.54 \pm 5.55$ \\
\hline Vertical cephalic index $(\mathrm{VCl})$ & $78.31 \pm 5.19$ & $78.32 \pm 4.67$ & $78.27 \pm 6.43$ \\
\hline Transverse cephalic index $(\mathrm{TCl})$ & $103 \pm 7.78^{*}$ & $100 \pm 8.67$ & $101.81 \pm 8.02$ \\
\hline
\end{tabular}

The mean cephalic indices: horizontal $(\mathrm{HCl})$, vertical $(\mathrm{VCl})$ and transverse (TCl) in the males and the females were found to be $79.13 \pm 5.56$, $78.31 \pm 5.19,103 \pm 7.78$ and $78.32 \pm 6.40,78.32$ $\pm 4.67,100 \pm 8.67$ respectively (Table-I). Thus male subjects in our sample had a significantly higher $\mathrm{HCl}$ and $\mathrm{TCl}$ than females $(\mathrm{p}<0.001)$. The vertical cephalic index, however, did not exhibit any difference in significance between the two sexes.

Our observations as for the shape of the head indicated a mixed pattern; according to the horizontal cephalic index most of the subjects fell in the mesocephalic category of craniotype followed by the dolicocephalic both for the males and the females (Table-II).Majority of subjects in our study indicated to be having hypsicephalic category both in the males and females. Although a small number of females indicated orthocephalics type of cranium, no males belonged to this category (Table-III). The dominant majority belonged to acrocephalics followed by metriocephalics in a small number, according to the analysis of transverse cephalic index. In our study we did not observe any Tapeiocephalic type of cranium(Table-IV).

\begin{tabular}{|c|c|c|c|}
\hline Head shape & $\begin{array}{c}\text { Male } \\
\text { (\%age) }\end{array}$ & $\begin{array}{c}\text { Female } \\
\text { (\%age) }\end{array}$ & $\begin{array}{c}\text { Combined } \\
\text { (\%age) }\end{array}$ \\
\hline Dolichocephalic & $34.1^{\star}$ & 31.9 & 33.1 \\
\hline Mesocephalic & 47.4 & 43.6 & 45.7 \\
\hline Brachycephalic & 12.3 & 12.7 & 12.4 \\
\hline Hyperbrachycephalic & 6.2 & 11.8 & 8.8 \\
\hline
\end{tabular}

Table-II. Frequencies of the categories of head types according to horizontal cephalic index $(\mathrm{HCl})$

$$
\star P<0.05
$$

\begin{tabular}{|c|c|c|c|}
\hline Head shape & Male & Female & Combined \\
\hline Hypsicephalic & 100 & 97.6 & 98.4 \\
\hline Orthocephalic & $0^{\star}$ & 3.4 & 1.6 \\
\hline Chamaecephalic & 0 & 0 & 0 \\
\hline
\end{tabular}

Table-III. Frequencies of the categories of head types according to vertical cephalic index ( $\mathrm{VCI})$ ${ }^{\star} P<0.05$

\begin{tabular}{|c|c|c|c|}
\hline Head shape & Male & Female & Combined \\
\hline Metriocephalic & $1 .{ }^{\star}$ & 3.7 & 2.6 \\
\hline Acrocephalic & 98.1 & 96.3 & 97.4 \\
\hline Tapeinocephalic & 0 & 0 & 0 \\
\hline
\end{tabular}

Table-IV. Frequencies of the categories of head types according to transverse cephalic index $(\mathrm{TCI})$ $\star P<0.05$

\section{DISCUSSIONS}

Racial characteristics of a population are expressed in phenotype skeletal morphology but their best and most obvious expression is in the skull. ${ }^{10,11}$ Therefore cranial morphometry and hence the cephalic indices establish the most significant characteristics for defining the racial difference. ${ }^{11,12}$ Our present study is the first of its kind to record useful data regarding the cephalic indices and craniotypes in an adult South Punjab population.

Comparison of $\mathrm{Cl}$ between parents, offsprings and their siblings can give a clue towards genetic transmission of inherited characteristics. Skull measurements are also important for facial reconstruction in cases of disputed identity. ${ }^{13,14}$ Cephalometry remains to be the most popular and use full method for investigating the craniofacial skeletal morphology. ${ }^{15,16}$ The methods being simple and practicable can be easily applied for assessment of such characteristics to a 
population.

The mean horizontal cephalic index found in our study was lower than those reported for the Turkman ${ }^{17}$, Indians ${ }^{18}$,Mapuche individuals in Chile ${ }^{19}$, native Fars $^{20}$, European people in Mediterranean area ${ }^{21}$, North Europeans ${ }^{22}$, Japanese ${ }^{23}$, and higher than in Iranians. ${ }^{24}$ This observation reinforces the previous conclusion that racial variety exists in the cephalic indices of different populations.

In the present study mesocephalic was by far the commonest craniotype followed by dolicocephalic both in the male and female subjects. This is in contrast with observations recorded by Bhatia et $\mathrm{al}^{25}$ in Indian population. According to Bharati et $^{26}$ al in tropical zones head from is longer(dolichocephalic), while in temperate zones the shape of head from is round (mesocephalic or brachycephalic). Genetic and environmental factors have been suggested for the presence of variations in cephalic indices amongst groups of population. ${ }^{25,26}$

In our study according to the vertical cephalic index hypsicephalic while according to the transverse cephalic index the acrocephalic were the predominant craniotypes. This data may provide useful record for later reference.

Cranial measurements are different because they depend upon different gene expression in various races and ethnic group and are therefore a reliable determinant. An interesting observation in this regard is the first generation of Japanese immigrants in Hawaii in which it was observed that they had a higher cephalic index than their parents. ${ }^{27}$ Dietary habits have also been shown to modulate the craniofacial form of people. ${ }^{28}$

The cephalic indices and shapes presented here are valid only for adult population; skull dimensions vary with age and reach their maximum before twenty years. This data may be useful for forensic purposes and later research in this area. During interpretation of a skull radiograph baseline data is required for comparison especially so in cases where cerebral atrophy or hydrocephalus is suspected or an abnormal variation in skull is in question.

The study sample was taken mainly from the city of Multan and as such may not be representative of all the population in southern Punjab. Further work therefore is required with a larger sample and covering various rural and urban segments of the region.

\section{CONCLUSION}

The study provides baseline cephalometric data from adult population of Southern Punjab with its potential clinical and forensic application and may be useful reference for future research.

Copyright (C) 06 July, 2015.

\section{REFERENCES}

1. Argyropoulos E and Sassouni V. Comparison of the dentofacial patterns for native Greek and AmericanCaucasian adolescents. Am J Orthodontics and Dentofacial Orthopedics 1989; 95:238-49.

2. Grant T M and Peter AM. Size and shape measurement in contemporary cephalimeyrics, Eur $\mathrm{J}$ of orthodontics 2003; 25(3):231-42.

3. Williams P, DysonM,Dussak JE, Bannister LH, Berry MM, Collins P and Ferguson MWJ. Gray's anatomy. In: Skeletal system..London:Churchill Livingston. 1995; 38th Ed: 607-12.

4. Del Sol M. Cephalic index in a group of mapuche individuals in the IX Region of Chile.IntJMorphol. 2005; 23 (3):241-6.

5. Rabey GP. Craniofacial morphanalysis.Proc. R. Soc. Med 1971; 64:103-11.

6. Golalipour M. J.The Effect of Ethnic Factor on Cephalic Index in 17-20 Years Old Females of North of Iran.IntJMorphol 2006;24:319-22.

7. Harper C, Krill, J, Raven D and Jones N. Intracranial cavity volumes: a new method and its potential applications.Neuropathol. AppINeurobiol 1984;10:2532.

8. Abolhasanzadeh A and Farahani MR. Standarded international classification of head shapes of 22-24 years old in Tehran. J Res Med 2003; 26:281-5.

9. Rexhepi A and Meka V. Cephalofacial morphological characteristics of Albanian Kosova population.Int. J. 
Morphol 2008; 26:935-40.

10. Oladipo GS and Paul CW. Anthropometric comparison of cephalic indices between the Urhobo and Itsekiri ethnic group of Nigeria. Global J. Pure Appl. Sci.2009;15:65-7.

11. Williams, P. L.; Bannister, L. H.; Berry, M. M.; Collins, P.; Dyson, M.; Dussek, J. E. Gray's Anatomy: The anatomical basis of medicine and surgery. Churchill Livingstone, New York 2000; 38th Ed: 632-645.

12. Argyropoulos, E. \&Sassouni, V. Comparison of the dentofacial patterns for native Greek and AmericanCaucasian adolescents.Am. J. of orthodontics and dentofacial orthopedics1989;95:238-49.

13. Shah, G. V. \&Jadhav, H. R. The study of cephalic index in students of Gujarat.J. Anat. Soc. India2004;53(1):25-26.

14. Sekla, B. \&Soukup, F. Inheritance of the cephalic index. Am. J. Phys. Anthrop.2005;30(1):137-40.

15. Mclntyre, G. T. \&Mossey, P. A. Size and shape measurement in contemporary cephaometrics. Eur. J. Orthod.2003;25:231-42.

16. Vojdani, Z.; Bahmanpour, S.; Momeni, S.; Vasaghi, A.; Yazdizadeh, A.; Karamifar, A.; Najafifar, A.; Setoodehmaram, S. \&Mokhtar, A. Cephalometry in 14-18 years old girls and boys of Shiraz-Iran high school. Int. J. Morphol.2009;27:101-4.

17. Golalipour, M. J.; Jahanshahi, M. \&Haidari, K. Morphological evaluation of head in Turkman males in Gorgan-North of Iran. Int. J. Morphol.2007;25:99-102.

18. Shah, G. V. \&Jadhav, H. R. The study of cephalic index in students of Gujarat. J. Anat. Soc. India 2004;53:2526.
19. Del Sol, M. Cephalic index in a group of Mapuche individuals in the IX region of Chile. Int. J. Morphol.2005;23:241-6.

20 Golalipour, M. J. The variation of head shapes in 1720 years old native Fars male in Gorgan-North of Iran. Int. J. Morphol.2006;24:187-90.

21. García, H. F. \& Lips, M. W. Contribución al estudio delíndicecefálico en chilenos. An. Anat. Norm.1986a; 4:120-3

22. García, H. F. \& Lips, M. W.Variaciones-delíndicecefálicochil-enossegunas-cendencia. An. Anat. Norm. 1986b; 4:117-9.

23. Nakashima, T. Brachycephalization in the head form of school girls in North Kyushu. J UOEH.1986;8: 4114.

24. Abolhasanzadeh, A. \&Farahani, M. R. Standarded international classification of head shapes of 22-24 years old in Tehran. J Res Med 2003; 26:281-5.

25. Bhatia, M.; Thin, J.; Debray, H. \&Cabanes, J. Étudeanthropologiqueetgenetique de la population du nord de l'Inde. Bull EtMem. Soc. d'Anthrop. de Paris 1955; 10: 199- 213.

26. Bharati S, Som S, Bharati $P$ and Vasulu TS. Climated and head from in India. American Journal of Human Biology. 2001;13(5): 626-34.

27. Heravi, F. \&Zieaee, H. Assessing the importance of cephalic and facial indices in a group of 12 years old boys in Mashhad.Beheshti Univ. Dent. J.2002; 20:11924.

28. Kasai, K.; Richards, T. C. \& Brown, T. Comparative study ofcraniofacial morphology in Japanese and Australianaboriginal populations. Hum. Biol.1993, 65:821-34.

\begin{tabular}{|c|c|c|c|}
\hline \multicolumn{4}{|c|}{ AUTHORSHIP AND CONTRIBUTION DECLARATION } \\
\hline Sr. \# & Author-s Full Name & Contribution to the paper & Author $=s$ Signature \\
\hline 2 & $\begin{array}{l}\text { Mohammad Afzal Khan } \\
\text { M. Naeem Chaudhary Faris }\end{array}$ & $\begin{array}{l}\text { All authors contributed } \\
\text { equally and extensively to } \\
\text { the work presented in this } \\
\text { paper. }\end{array}$ & \\
\hline 3 & Mohammad Noor Altaf & & \\
\hline
\end{tabular}

